\title{
PELAKSANAAN PEMBERIAN INFORMED CONSENT DAN KELENGKAPAN INFORMASI DI RSU JATI HUSADA KARANGANYAR TAHUN 2014
}

\author{
${ }^{1}$ Sekar Arum Kencananingtyas, ${ }^{2}$ Tri Lestari, ${ }^{3}$ Harjanti \\ ${ }^{1}$ Mahasiswa APIKES Mitra Husada Karanganyar, ${ }^{2,3}$ Dosen Apikes Mitra Husada \\ ${ }^{1}$ Tyashbeiby@yahoo.co.id, ${ }^{2}$ Fitri.Apikesmitra@yahoo.co.id, ${ }^{3}$ jhan_thie18@yahoo.com
}

\begin{abstract}
Hospitals Jati Husada Karanganyar on providing information relating to informed consent is not informative. In because patients who will be there are 2 types of medical treatment that the patient and the patient's general patient One Day Care (ODC). For a general explanation of the patient while the patient information clearer One Day Care $(O D C)$ provision of information only described in general terms. The purpose of this study was to determine the implementation of the provision of informed consent and completeness of information that covers 6 main topics, namely Diagnosis of disease, objective, risk measures, risk of complications, alternative actions, Prognosis. This type of research is descriptive qualitative and quantitative. This study used interviews and observation guidelines. Qualitative data processing techniques with Data Reduction (Data Reduction), Presentation of Data (Data Display), Consclusion Drawing / Quantitative verivication while the collection (Collecting), and Presenting (Narrative) or presentation of data, analysis of the data used is descriptive qualitative and quantitative analysis. The results show the implementation of the provision of informed consent after receiving clear information from the initial patients in the emergency room entrance and approve medical treatment by signing an informed consent to complete the service. Informed Consent form filling completeness lowest identification on No.KTP / SIM 15 (100\%) incomplete and type of information conveyed by the highest doctor medical treatment 15 (100\%). Hospitals are advised Hospitals Jati Husada Karanganyar have fixed procedures on patient care procedures One Day Care (ODC) and design in a revised informed consent form according to standard hospital care with a minimum of information includes the type of diagnosis (WD / DD), Primary Diagnosis, Medical Action, Indication actions, Procedures, Objectives, Risks, Complications, Prognosis, and Risk Alternative formats are based on the Indonesian medical counsil.
\end{abstract}

Keyword: Informed Consent, Completeness of information

\begin{abstract}
ABSTRAK
RSU Jati Husada Kabupaten Karanganyar pada pemberian informasi yang berkaitan dengan informed consent belum informatif. Di karenakan pasien yang akan dilakukan tindakan medis ada 2 jenis pasien yaitu pasien umum dan pasien One Day Care (ODC). Untuk pasien umum penjelasan informasi lebih jelas sedangkan pasien One Day Care (ODC) pemberian informasi hanya dijelaskan secara umum saja. Tujuan dari penelitian ini adalah mengetahui pelaksanaan pemberian informed consent dan kelengkapan informasi yang mencakup 6 hal pokok yaitu Diagnosa penyakit, Tujuan, Risiko tindakan, Risiko komplikasi, Alternatif tindakan, Prognosis. Jenis Penelitian ini adalah deskriptif kualitatif dan kuantitatif. Penelitian ini menggunakan pedoman wawancara dan pedoman observasi. Teknik pengolahan data kualitatif dengan Reduksi Data (Data Reduction), Penyajian Data (Data Display), Consclusion Drawing/verivication sedangkan Kuantitatif dengan Pengumpulan (Collecting), dan Memaparkan (Narasi) atau penyajian data, analisis data yang digunakan adalah analisis deskriptif kualitatif dan kuantitatif. Hasil penelitian menunjukkan pelaksanaan dalam pemberian Informed Consent setelah mendapatkan informasi yang jelas di UGD dari awal pasien masuk dan menyetujui tindakan medis dengan melakukan penandatanganan Informed Consent hingga selesai pelayanan. Kelengkapan formulir Informed Consent pengisian identifikasi terendah pada No.KTP/SIM 15 (100\%) tidak lengkap dan Jenis informasi yang disampaikan oleh dokter tertinggi yaitu tindakan medis 15 (100\%).Disarankan RSU Jati Husada Karanganyar
\end{abstract}


memiliki prosedur tetap tentang prosedur pelayanan pasien One Day Care (ODC) dan desain formulir informed consent di revisi sesuai standart pelayanan minimal rumah sakit dengan memuat jenis informasi tentang diagnosis (WD/DD), Dasar Diagnosis, Tindakan Kedokteran, Indikasi Tindakan, Tata Cara, Tujuan, Risiko, Komplikasi, Prognosis, Alternatif dan Risiko yang berpedoman pada format Konsil Kedokteran Indonesia.

Kata Kunci: Informed Consent, Kelengkapan Informasi

\section{PENDAHULUAN}

Menurut Peraturan Menteri Kesehatan Republik Indonesia No.290/MENKES/PER/III/2008 yang berkaitan dengan aspek hukum adalah Informed Consent. Informed consent adalah persetujuan tindakan kedokteran yang diberikan oleh pasien atau keluarga terdekatnya setelah mendapatkan penjelasan secara lengkap mengenai tindakan kedokteran yang akan dilakukan terhadap pasien tersebut.

Keadaan Informed Consent sangat penting artinya bagi pelaksana pelayanan kesehatan, sebab dari Informed Consent akan lahir perjanjian atau kesepakatan kesehatan, adanya perjanjian kesehatan merupakan faktor penentu dan menumbuhkan rasa aman dan nyaman bagi seorang dokter atau tenaga kesehatan untuk menjalankan tugasnya sebagai pemberi pelayanan kesehatan, terutama bila dikaitkan dengan kemungkinan adanya perselisihan antara pasien dengan dokter atau rumah sakit dikemudian hari. Apabila dampaknya akan mempengaruhi terhadap tindakan medis, perawatan dan operasi.

Dari survey pendahuluan di Rumah Sakit Jati Husada Karanganyar prosedur pelaksanaan pemberian informed consent terdapat dua jenis pasien yaitu pasien umum dan pasien One Day Care (ODC). Untuk pasien umum dalam pelaksanaan pemberian informed consent diberikan secara lisan dan tertulis diikuti dengan penandatanganan surat pernnyataan persetujuan tindakan medis dari pihak keluarga pasien yang bersangkutan. Untuk pasien One Day Care (ODC) pelaksanaan pemberian informed consent dilakukan dengan penandatanganan dari pihak pasien dan petugas pelayan kesehatan. Informasi yang di sampaikan oleh dokter kepada pasien atau keluarga terdekat pada prosedur penyampaian persetujuan tindakan medik mencakup 6 hal pokok yaitu; Diagnosa penyakit, Tujuan dan prospek keberhasilan tindakan medik yang akan dilakukan, Resiko tindakan medik yang akan dilakukan, Resiko dan komplikasi yang mungkin terjadi, Alternatif tindakan, Proporsi penyakit.
Dari hasil survey di RSU Jati Husada Kabupaten Karanganyar terdapat 50 tindakan operasi pada bulan April tahun 2014, dan diantaranya terdiri dari beberapa jenis tindakan yang meliputi Apendictomy, Herniotomy, Laparotomy, Open Reduction Internal Fixation (ORIF), Open Reduction Internal (ORI), Removal Of Implant (ROI), Sinusitis, Ceasarea Section, Ca Mammae. Dimana tindakan itu pada formulir Informed Consent belum muncul informasi apa saja yang akan dijelaskan kepada pasien.

Oleh karena itu, penulis tertarik untuk melakukan penelitian dengan mengambil judul "Pelaksanaan Pemberian Informed Consent dan Kelengkapan Informasi Di RSU Jati Husada Kabupaten Karanganyar Tahun 2014"

\section{METODE PENELITIAN}

Jenis penelitian ini menggunakan jenis penelitian deskriptif Kualitatif dan Kuantitatif. Instrumen dan Cara Pengumpulan DataInstrumen Penelitian yang digunakan untuk mengumpulkan data adalah Pedoman observasi, Pedoman wawancara, Alat perekam suara atau tape recoder, Cara Pengumpulan Data, Observasi dan Wawancara terstruktur. Teknik Pengolahan data Kualitatif yaitu Reduksi Data (Data Reduction), Penyajian Data (Data Display) dan Conclusion Drawing / Verivication. Sedangkan teknik pengumpulan data Kuantitatif yaitu Pengumpulan (Collecting), Edit (Editing), Klasifikasi (Classification), Tabulasi (Tabulating) dan Pemaparan/Penyajian data (Narasi)

\section{HASIL}

Alur pelaksanaan pemberian Informed Consent

Di RSU Jati Husada Karanganyar dalam pelaksanaan pengisian dan penandatanganan formulir Informed Consent dilakukan di UGD, karena setiap pasien masuk baik pasien umum ataupun pasien One Day Care (ODC). Prosedur awal masuk rumah sakit 
kecuali pasien periksa ke dokter spesialis yang masuk di UGD. Petugas melakukan anamnesa terhadap pasien jika harus dilakukan tindakan operasi pihak pasien atau keluarga terdekat wajib mengisi dan menandatangani formulir informed consent.

Alur prosedur pelayanan pasien yang akan dilakukan tindakan medis di RSU Jati Husada Karanganyar terdapat 2 jenis pasien yaitu :

Pasien umum, petugas melakukan pendaftaran dan menganamnesa pasien, jika pasien tersebut harus dilakukan tindakan operasi maka dokter memberikan penjelasan informasi mengenai diagnosis, tujuan, risiko tindakan, alternatif tindakan, proporsi penyakit, jam dilakukannya operasi dan dokter yang merawat. Pihak pasien atau keluarga terdekat mengisi formulir dan menandatangani persetujuan tindakan medis di atas materai yang berjumlah 1 (satu) digunakan yaitu materai pertama yang menyatakan pertanggungjawaban pihak pasien kedua diatas materai dokter yang merawat dalam tindakan operasi.

Pasien One Day Care merupakan pasien rujukan dari rumah sakit lain atau dokter/perawat yang mengirim pasien tersebut untuk dilakukan tindakan operasi. Jadi pasien One Day Care yang datang di UGD petugas melakukan pemberian infus/anamnesa. Untuk jenis informasi dan semua perawatan sudah dijelaskan oleh dokter/perawat yang mengirim sebelum datang ke rumah sakit. menandatangani formulir persetujuan tindakan yang bermaterai yang sudah di sediakan oleh petugas. Pihak pasien atau keluarga terdekat mengisi formulir dan menandatangani persetujuan tindakan medis di atas materai yang berjumlah 1 (satu) yang digunakan yaitu materai yang menyatakan pertanggungjawaban pihak pasien.

Di RSU Jati Husada pelaksanaan pemberian persetujuan tindakan medis sudah sesuai dengan prosedur tetap rumah sakit, apabila tidak ada keluarga pasien yang dapat di minta persetujuannya. Untuk pasien yang benar-benar gawat dan harus dilakukan tindakan operasi, jika tidak ada keluarga yang mengantar pasien, di tangani terlebih dahulu demi keselamatan. Setelah pasien sadar ataupun selesai dilakukan tindakan. Petugas meminta data sosial pasien dan menanyakan keluarga terdekat pasien untuk mengisi dan menandatangani formulir informed consent.
Kelengkapan Pemberian Informasi pada Formulir Informed Consent.

Pada formulir Informed consent di RSU Jati Husada Karanganyar terdiri 3 bagian dalam pengisian identitas (Identifikasi), tindakan medis dan pengisian tanda tangan (Autentikasi) saksi lain sebagai berikut:

Tabel 1 Kelengkapan Pengisian Informed Consent

\begin{tabular}{|c|c|c|c|c|c|}
\hline \multirow{3}{*}{ No } & \multirow{3}{*}{$\begin{array}{c}\text { Jenis } \\
\text { Informasi }\end{array}$} & \multicolumn{4}{|c|}{$\begin{array}{c}\text { Kelengkapan Pengisian Formulir } \\
\text { Surat Pernyataan Medis }\end{array}$} \\
\hline & & \multicolumn{2}{|c|}{ Lengkap } & \multicolumn{2}{|c|}{ Tidak Lengkap } \\
\hline & & $\mathrm{Jml}$ & $\%$ & Jml & $\%$ \\
\hline 1 & $\begin{array}{l}\text { Nama } \\
\text { Keluarga }\end{array}$ & 15 & 100 & - & - \\
\hline 2 & Umur & 15 & 100 & - & - \\
\hline 3 & Pekerjaan & 15 & 100 & - & - \\
\hline 4 & Alamat & 15 & 100 & - & - \\
\hline 5 & $\begin{array}{l}\text { No.KTP / } \\
\text { SIM }\end{array}$ & - & - & 15 & 100 \\
\hline 6 & $\begin{array}{l}\text { Hubungan } \\
\text { dengan pasien }\end{array}$ & 15 & 100 & - & - \\
\hline 7 & Nama Pasien & 15 & 100 & - & - \\
\hline 8 & Umur & 3 & 20 & 12 & 80 \\
\hline 9 & Pekerjaan & 12 & 80 & 3 & 20 \\
\hline 10 & Alamat & 9 & 60 & 6 & 40 \\
\hline 11 & $\begin{array}{l}\text { Tindakan } \\
\text { Medis }\end{array}$ & 15 & 100 & - & - \\
\hline 12 & $\begin{array}{l}\text { Tempat dan } \\
\text { Tanggal }\end{array}$ & 15 & 100 & - & - \\
\hline 13 & $\begin{array}{l}\text { Yang } \\
\text { Menyatakan }\end{array}$ & 9 & 60 & 6 & 40 \\
\hline 14 & $\begin{array}{l}\text { Dokter Yang } \\
\text { Merawat }\end{array}$ & 15 & 100 & - & - \\
\hline 15 & Saksi Petugas & 5 & 33,3 & 10 & 66,6 \\
\hline 16 & Saksi Lain & - & - & 15 & 100 \\
\hline
\end{tabular}

Berdasarkan tabel 4.1 dari hasil observasi diketahui bahwa kelengkapan pengisian identitas pasien dari formulir Informed Consent tertinggi sebanyak 15 kasus berdasarkan nama pasien, umur, pekerjaan dan alamat dilengkapi (100\%) sedangkan pengisian identitas keluarga pasien yang melengkapi formulir Informed

Consent terendah pada pengisian No.KTP/SIM $15(100 \%)$ tidak selalu di lengkapi dengan alasan keefektifan waktu dalam pengisian formulir. Jenis tindakan terisi lengkap 15 (100\%).

Jumlah persentase tertinggi pada formulir persetujuan pernyataan medis Informed Consent berdasarkan 
auntentikasi nama terang dan tanda tangan Dokter Penanggug Jawab Pasien (DPJP) yaitu sebanyak 15 $(100 \%)$ dan terendah $15(100 \%)$ tidak lengkap pada pengisian tanda tangan perawat dan saksi yang tidak mencantumkan nama terang dan tandatangan.

\section{PEMBAHASAN}

Alur pelaksanaan prosedur pelayanan pasien di RSU Jati Husada Karanganyar.

Alur prosedur pelayanan pasien yang akan dilakukan tindakan dengan Informed Consent berdasarkan hasil observasi dan wawancara dengan dokter, perawat/ bidan petugas pelayan kesehatan yang dilaksanakan di UGD terdiri dari 2 jenis pasien yaitu :

a. Pasien umum yaitu pasien datang sendiri atau dengan keluarga pasien untuk dilakukan pemeriksaan oleh petugas. Kemudian dokter atau perawat melakukan anamnesa, jika pasien tersebut gawat dan harus dilakukan tindakan operasi maka dokter akan menjelaskan prosedur dan informasi apa saja yang nantinya akan dilakukan pada saat dilakukannya tindakan operasi, dokter yang melakukan tindakan medik bertanggung jawab memberikan informasi dan penjelasan. Apabila berhalangan dapat diwakilkan kepada dokter jaga UGD atas perintah Dokter Penanggung Jawab Pasien (DPJP) dengan sepengetahuan pasien yang bersangkutan. kemudian pasien atau keluarga pasien wajib mengisi dengan lengkap identitas dan menandatangani formulir surat pernyataan (Informed Consent) yang bermaterai.

b. Pasien One Day Care (ODC) yaitu pasien kiriman dari rumah sakit lain, dokter atau perawat yang ada di rumah sakit. pasien tersebut pada saat di UGD hanya di beri tindakan pemasangan infus, karena prosedur dan jenis informasi sudah dijelaskan oleh pengirim dokter/perawat sebelumnya. Oleh karena itu pasien atau keluarga terdekat wajib mengisi dan menandatangani surat pernyataan (Informed Consent) dengan lengkap dan bermaterai yang di sediakan oleh dokter UGD. Dalam SOP di jelaskan bahwa dokter yang melakukan tindakan medik bertanggung jawab memberikan informasi dan penjelasan. Apabila berhalangan dapat diwakilkan kepada dokter lain dengan sepengetahuan pasien yang bersangkutan. Dan informasi yang di sampaikan secara lisan, informasi tertulis hanya sebagai pelengkap saja. c. Berdasarkan SOP RSU Jati Husada Karanganyar mengenai penyampaian persetujuan tindakan medik (Informed consent) No.RM 01.01.023 No. Revisi A, Tanggal Terbit 10 Mei 2010. Jati Husada Karanganyar tentang penyampaian persetujuan tindakan medik (Informed Consent) pada point 6 dijelaskan tidak di perlukan materai. Dalam alur pelayanan pasien yang akan dilakukan tindakan belum sesuai. Karena di rumah sakit ditempel 1 materai dari pihak yang bertanggung jawab pasien.

Di RSU Jati Husada Karanganyar belum ada standart operasional prosedur mengenai alur prosedur pasien One Day Care (ODC). Untuk memudahkan pelayanan dan pemberian informasi kepada pasien lebih efektif dan informatif. Berdasarkan Permenkes Nomor585/MENKES/PER/IX/1989 tentang persetujuan tindakan medis menyatakan bahwa pasien yang berada dalam keadaan tidak sadar atau pingsan dan tidak didampingi keluarga terdekat secara medis berada dalam keadaan gawat-darurat yang memerlukan diambilnya tindakan medis segera untuk kepentingannya maka tidak diperlukan persetujuannya dari siapapun".

Kelengkapan pemberian informasi pada formulir informed consent

Di RSU Jati Husada karanganyar di dalam formulir hanya terdapat 1 kolom mengenai jenis tindakan medis dan dicatat oleh dokter sebagai bukti tertulis bahwa pasien telah dilakukan tindakan sesuai prosedur dan untuk klaim pembayaran administrasi sesuai jenis tindakan. Dalam formulir Informed Consent jenis informasi sesuai dengan standar pelayanan minimal.

Menurut keputusan KKI Nomor 18/KKI/KEP/ IX/2006 tertanggal 21 September 2006 peraturan Konsil kedokteran Indonesia (KKI) tentang Manual Persetujuan Tindakan Medis yang berkaitan dengan jenis informasi yang akan dilakukan terhadap pasien dengan mengacu kepada kepustakaan, KKI melalui buku manual ini memberika 12 kunci informasi yang sebaiknya diberikan kepada pasien yaitu:

a. Diagnosis dan prognosis secara rinci apabila tidak diobati.

b. Ketidakpastian tentang diagnosis (diagnosis kerja dan diagnosis banding) termasuk pilihan pengobatan sebelum dilakukan pengobatan.

c. Tujuan dari rencana pemeriksaan dan pengobatan; rincian dari prosedur atau 
pengobatan yang dilaksanakan, termasuk tindakan subsider seperti penanganan, bagaimana pasien harus mempersiapkan diri, rincian apa yang dialami pasien selama dan sesudah tindakan, termasukefek samping yang biasa terjadi dan yang serius.

d. Untuk setiap tindakan, diperlukan keterangan tentang kelebihan/keuntungan dan tingakta kemungkinan keberhasilannya, dan diskusi tentang kemungkinan resiko yang serius atau sering terjadi dan perubahan gaya hidup. sebagai akibat dari tindakan tersebut.

e. Nyatakan bila tindakan tersebut masih ekpserimental.

f. Bagaimana dan kapan kondisi pasien dan akibat sampingannya akan dimonitor atau dinilai kembali.

g. Nama dokter yang bertanggung jawab secara keseluruhan untuk pengobatan tersebut.

h. Bila melibatkan dokter yang sedang mengikuti pelatihan atau pendidikan, maka sebaiknya dijelaskan perananannya didalam rangkaian tindakan yang akan dilakukan.

i. Mengingat kembali bahwa pasien dapat mengubah pendapatnya setiap waktu.

j. Mengingatkan bahwa pasien berhak memperoleh pendapat kedua dari dokter lain.

k. Bila memungkinakan, juga diberitahu tentang perincian biaya.

Di RSU Jati Husada berdasarkan hasil observasi dan wawancara untuk penyampaian informasi kepada pasien hal yang disampaikan diagnosis, tujuan, alternatif tindakan. Pada isi formulir informed consent hanya di tulis pada tindakan medis yang dilakukan dalam lisan di jelaskan tentang diagnosis penyakitnya, jenis tindakan, jam operasi, dokter yang menangani saat tindakan.

Sebaiknya diberikan juga penjelasan yang berkaitan dengan pembiayaan, penjelasan dilakukan oleh dokter yang akan melakukan tindakan medis itu sendiri. Di dalam standar operasional prosedur rumah sakit tentang penyampaian persetujuan tindakan medik (Informed Consent) mencakup 6 hal pokok yaitu diagnosa penyakit, tujuan dan prospek keberhasilan tindakan medik yang akan dilakukan, resiko tindakan medik yang akan dilakukan, resiko dan komplikasi yang mungkin terjadi, Alternatif tindakan medik serta resikonya masing-masing, proporsi penyakit apabila tindakan medik tersebut dilakukan atau tidak dilakukan. Tujuan penjelasan yang lengkap agar pasien menentukan sendiri keputusannya sesuai pilihan dia sendiri (informed dessicion). Menurut Amir (2008) pasien juga berhak untuk menolak tindakan medis yang dianjurkan dan berhak untuk meminta pendapat orang lain, dan dokter yang merawatnya (Second opinion)

Fungsi dari Informed consent sendiri menurut Guwandi (2005) yaitu promosi dan perorangan, proteksi dari pasien dan subyek, menimbulkan rangsangan kepada profesi medis untuk mengadakan intropeksi diri terhadap diri sendiri, promosi dan keputusan-keputusan rasional, keterlibatan masyarakat dalam memajukan prinsip otonomi sebagai suatu nilai sosial dan mengadakan pengawasan dalam penyelidikan biomedik.

Kelengkapan formulir berdasarkan identifikasi pengisian identitas pasien dari formulir Informed Consent tertinggi sebanyak 15 kasus berdasarkan nama pasien, umur, pekerjaan dan alamat dilengkapi $(100 \%)$ sedangkan pengisian identitas keluarga pasien yang mengisi formulir Informed Consent terendah pada pengisian No.KTP/SIM 15 (100\%) tidak selalu diisi dengan alasan keefektifan waktu dalam pengisian formulir dan kurangnya pengetahuan pihak pasien arti pentingnya pengisian nomor identitas diri dan sebagai bukti keabsahan dalam suatu perkara.

Kelengkapan formulir informed consent setelah mendapatkan informasi yang jelas, benar dan lengkap berdasarkan hasil obsevasi jumlah persentase tertinggi dalam pemberian jenis informasi yang disampaikam dokter kepada pasien pada jenis tindakan, diagnosis penyakit, tujuan, dan prognosis sebesar $15(100 \%)$ dan persentase terendah mengenai resiko tindakan $8(60 \%)$. Dalam kelengkapan pemberian informasi belum sesuai dengan Standart Pelayanan Minimal 100\% dikarenakan di rumah sakit ini dalam pelayanan yang akan dilakukan tindakan operasi terdapat 2 jenis pasien yaitu pasien umum dan One Day Care (ODC). Sehingga dalam pemberian informasi kurang informatif yang di sampaikan dan kurang lengkapnya desain formulir tentang jenis informasi informed consent hanya terisi tindakan medis dan dicatat oleh dokter sebagai bukti tertulis bahwa pasien telah dilakukan tindakan sesuai prosedur dan untuk klaim pembayaran administrasi sesuai jenis tindakan. Untuk itu informed consent sangat di perlukan dalam proses perjanjian antara dokter dengan pasien pada saat akan dilakukan tindakan medis (Depkes RI, 2008).

Berdasarkan autentikasi nama terang dan tanda tangan Dokter Penanggug Jawab Pasien (DPJP) 
yaitu sebanyak $15(100 \%)$ lengkap dan terdapat 10 $(66,6 \%)$ tidak lengkap pada pengisian tanda tangan dan nama terang pada saksi petugas dikarenakan petugas tidak mengisi nama terang perawat yang bertanggung jawab dan hanya dikosongkan saja, faktor lain ketidaklengkapan pengisian nama terang dan tanda tangan saksi lain sebanyak 15 $(100 \%)$ dikarenakan kurangnya pengetahuan pasien mengenai penulisan dan tandatangan. Dalam hal tersebut dalam dapat disimpulakn kurangnya tenaga pelayan kesehatan di rumah sakit dan kurangnya kesadaran akan pentingnya penandatanganan pada kelengkapan formulir informed consent. Apabila formulir tidak terdapat nama penanggung jawab, mengakibatkan petugas sulit menentukan pihak yang bertanggungjawab dalam pelayanan yang diberikan kepada pasien (Depkes RI, 2006)

Pada desain formulir persetujuan tindakan kedokteran dan penolakan tindakan kedokteran perlu adanya revisi sesuai dengan contoh format Konsil Kedokteran Indonesia (KKI) dimana jenis informasi dokter dituntut untuk menyampaikan atau menjelasakan Informed Consent secara lengkap dalam membubuhkan tanda tangan, agar pasien tersebut mengerti maksud dan tujuan dari dilakukannya persetujuan tindkan agar pasien tidak cenderung hanya mengikuti instrukis dokter. Dan sudah di lampirkan sesuai prosedur tindakan medis terkait tentang desain formulir Informed Consent. ( lampiran 3 dan 4 ).

\section{SIMPULAN}

Dalam alur prosedur pelaksanaan pelayanan pasien yang akan dilakukan yaitu pasien mendaftar di tempat pendaftaran, masuk poli spesialis/One Day Care ataupun UGD, pasien dilakukan anamnesa oleh perawat, dokter memberi instruksi kepada pasien apakah pasien akan dilakukan operasi jika iya pasien atau pihak keluarga mengisi kelengkapan Informed Consent, kemudian pasien di bawa ke kamar operasi untuk dilakukan tindakan setelah selesai jika pasien One Day Care (ODC) pihak keluarga melakukan prosess administrasi karena pasien segera dibawa pulang sesuai kondisi pasien. Jika pasien umum akan kembali ke bangsal proses pemulihan (Rehabilitasi Medik).

Kelengkapan jenis informasi yang disampaikan kepada pasien baik secara lisan dan tertulis pada formulir informed consent: a. Kelengkapan formulir Informed Consent berdasarkan identifikasi pada pengisian identitas pasien tertinggi sebanyak 15 kasus berdasarkan nama pasien, umur, pekerjaan dan alamat dilengkapi (100\%), terendah pada pengisian No.KTP/SIM 15 (100\%). Kelengkapan pada pengisian informasi tindakan medis $15(100 \%)$.

b. Kelengkapan formulir informed consent berdasarkan autentikasi untuk persentase tertinggi Dokter Penanggung Jawab Pasien (DPJP) sebanyak 15 (100\%) diisi secara lengkap, perserntase terendah adalah tanda tangan dan nama terang saksi atau petugas 15 (100\%) tidak diisi dikarenakan masih kurangnya tenaga perawat yang bertugas di rumah sakit.

\section{DAFTAR PUSTAKA}

Departemen Kesehatan Republik Indonesia. 2006. Pedoman Penyelenggaraan dan Prosedur Rekam Medis Rumah Sakit di Indonesia Revisi II. Jakarta : Depkes RI

2008. Peraturan Menteri Kesehatan republik Indonesia Nomor 269/ MENKES/PER/III/2008. tentang Rekam Medis.Jakarta: Depkes RI

2008. Peraturan MenteriKesehatan Nomor 290/MENKES/PER/III/2008 Aspek hukum. Diakses melalui www.ppjk.depkes. go.id. diunduh tanggal 18 Maret 2014

Guwandi J.2005. Rahasia Medik. Jakarta: FKUI

Hanafiah JM \& Amir A.2009.Etik Kedokteran dan Hukum Kesehatan. Jakarta: ECG

Hatta, G.R. 2013. Bab 5 Tujuan, Penggunaan dan Fungsi Rekam Medis. Editor Hatta, G. Pedoman Manajemen Informasi kesehatan di Sarana Pelayanan Kesehatan. Jakarta :Universitas Indonesia (UI Press). Hal: 79

Konsil Kedokteran Indonesia 2006, Buku Manual Persetujuan Tindakan Kedokteran, Jakarta: KKI

Notoatmodjo, S. 2005. Metodologi Penelitian Kesehatan. Jakarta: Rineka Cipta. 2010. Metodologi Penelitian Kesehatan. Jakarta: Rineka Cipta.

Sudra, RI.2013. Rekam Medis. Banten : Universitas Terbuka

Sugiono.2013. Pendekatan Kuantitatif,Kualitatif dan $R \& D$. Bandung: Alfabeta 